\title{
Épocas de semeadura de girassol 'safrinha', em sucessão a girassol no cerrado tocantinense
}

\section{Times of sowing sunflower 'off season', in succession to sunflower in the cerrado tocantinense}

\author{
Aristóteles Capone ${ }^{1 *}$, Hélio Bandeira Barros ${ }^{1}$, Elonha Rodrigues dos Santos ${ }^{1}$, Emerson \\ Castro Ferraz ${ }^{1}$, Adão Felipe dos Santos ${ }^{1}$ e Rodrigo Ribeiro Fidélis ${ }^{1}$ \\ ${ }^{I}$ Departamento de Agronomia; Universidade Federal do Tocantins; 77402-970; Gurupi - TO - Brasil.
}

\begin{abstract}
The sunflower (Helianthus annuus L.) is considered a culture of great plasticity, has important characteristics like tolerance to different abiotic factors, drought and extreme temperatures. In that context the culture becomes favorable to the safrinha, in with direct sowing optimizes the use of the earth, machines, labour and creation of jobs in the producing region. The objective of this study was to evaluate cultivars of sunflower (Hélio 250 - H250, Hélio 251 - H251, Hélio 358 - H358, Hélio 360 - H360 e Hélio 884 - H884) in four sowing times (EP1 -15/03/2009; EP2 28/03/2009; EP3 - 09/04/2009 e EP4 - 01/05/2009) direct on sunflower straw, safrinha 2009, in Gurupi, South part of the State of Tocantins. The experimental design was randomized blocks in factorial scheme $4 x 5$ (sowing time $x$ cultivars) with three repetitions. There was significant interaction between sowing times and cultivars for all traits. There was reduction in all traits with retardation of the sowing. Highest productivity of achenes was obtained when sunflower was grown in the second sowing time. The cultivar H884 had the best performance for most of the analyzed variables at different times of sowing.
\end{abstract}

Key-words: Helianthus annuus L., cultivars, straw

\section{INTRODUÇÃO}

O girassol (Helianthus annuus L.) apresenta características importantes, como maior tolerância à seca e a temperaturas extremas, quando comparado com a maioria das espécies cultivadas no Brasil. Suas sementes podem ser utilizadas para a fabricação de ração animal e para a extração de óleo de alta qualidade para consumo humano ou como matéria-prima para a produção de biodiesel (Leite et al., 2005). Seu óleo possui características culinárias e nutricionais valiosas, sendo uma excelente fonte de ácido linoléico (Castiglioni e Oliveira, 2005). Pode ser utilizados como alimento funcional tanto para humanos, quanto ruminantes, suínos e aves, além disso, pode ser utilizado para silagem como opção forrageira. Atualmente, está despertando grande interesse, pois representa uma alternativa de mercado para produção de matériaprima na obtenção de bicombustíveis (Villalba,
2008). No mundo, o girassol destaca-se como a quinta oleaginosa em produção de grãos, quarta em produção de farelo e terceira em produção de óleo. Os maiores produtores são: Rússia, Ucrânia, União Européia e Argentina (Lazzarotto et al., 2005). Essa cultura responde por cerca de $13 \%$ de todo óleo vegetal produzido no mundo e vem apresentando índices crescentes de produção e área plantada (Smiderle et al., 2005).

No Brasil, o girassol apresenta-se como cultura promissora, devido sua ampla adaptação e excelente qualidade do óleo, além de estar inserido no programa nacional de produção e uso de biodiesel (Ungaro, 2006). A cultura ocupa área de cultivo restrita, sendo que dos 75.000 hectares cultivados na safra 2008/2009 aproximadamente 71.500 hectares foram cultivados no Centro Sul e apenas 3.500 hectares nas regiões Norte/Nordeste (CONAB, 2010).

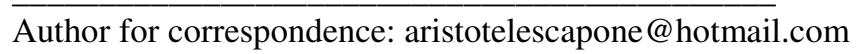


Sabe-se que na cultura do girassol ocorre interação entre genótipos e ambientes, havendo variação do comportamento de cultivares em função da região e época de plantio (Porto et al., 2007). Estes fatores podem ser responsáveis pelo insucesso da cultura, pois a carência de informações disponíveis sobre cultivares adaptadas e épocas de semeadura apropriadas para as diferentes regiões do país faz com que os produtores busquem outras alternativas.

Mas a partir de 2005 a cultura tem despertado o interesse de agricultores, técnicos e empresas devido à possibilidade de utilizar o óleo derivado desta na fabricação de biodiesel, esta demanda crescente possibilita forte expansão na área de cultivo de girassol, sendo a cultura apontada como uma nova alternativa econômica em sistemas de rotação/sucessão de culturas de grãos (Backes et al., 2008).

No Sudeste, o cultivo do girassol em sucessão a grandes culturas, tem-se sido boa alternativa para o agricultor, permitindo o aproveitamento de áreas irrigadas ou não, na entressafra, e de reforma de canavial, na safra, ou mesmo em áreas tradicionais (Gomes et al., 2004). A safrinha de girassol apresenta se como ótima para produção de óleo, tendo como atrativo um valor de mercado mais alto quando comparado ao óleo de soja para alimentação humana, além de diminuir a ociosidade das indústrias beneficiadoras, otimizar a utilização da terra, máquinas e mão-de-obra, gerando renda e empregos na região produtora.

Outro fator importante para as safrinhas é a utilização da semeadura direta, que tem como fundamentos a ausência de preparo do solo e permanência de cobertura através da rotação e sucessão de culturas, com isso aumenta o teor de matéria orgânica e qualidade do solo, melhora a conservação de água no solo, eleva a disponibilidade e prolongamento de água ao longo do ciclo da cultura, diminuindo os efeitos prejudiciais da estiagem no cultivo de safrinhas, fatores importantíssimo para o cerrado tocantinense.

O Estado do Tocantins apresenta localização estratégica, facilidade de escoamento, disponibilidade hídrica e terras agricultáveis, o que o potencializa como um futuro celeiro agrícola nas regiões do cerrado Brasileiro. Entretanto, ainda há uma enorme carência de estudos para cultura do girassol nessas regiões, principalmente referente à épocas de semeadura e interação genótipo $x$ ambiente, especialmente em condições de safrinha. Há poucas informações disponíveis sobre cultivares adaptadas e épocas de semeadura apropriadas para as diferentes regiões (Costa et al., 2000), sabe-se que o rendimento obtido pelo girassol depende da cultivar assim como das condições ambientais a que for submetida (Abreu et al., 2001), pensado nesta carência de informações para o norte do país, o presente trabalho teve como objetivo avaliar a produtividade cultivares de girassol em quatro épocas com semeadura direta sobre palhada de girassol na safrinha 2009, em Gurupi, no Sul do Estado do Tocantins.

\section{MATERIAL E METODOS}

O experimento foi conduzido no ano agrícola 2008/2009, na Universidade Federal do Tocantins, Campus Universitário de Gurupi, Estado do Tocantins $\left(11^{\circ} 43^{\prime} \mathrm{S}, 4^{\circ} 04^{\prime} \mathrm{W}\right.$ e altitude de 280 $\mathrm{m})$, a temperatura média anual varia de $22^{\circ} \mathrm{C}$ a $32^{\circ} \mathrm{C}$, com umidade relativa média do ar em torno de $76 \%$, precipitação anual média de $1.400 \mathrm{~mm}$, e solo do tipo Latossolo Vermelho Amarelo Distrófico (EMBRAPA, 1999).

As análises químicas e físicas do solo foram realizadas no laboratório de solos do Departamento de Solos da Universidade Federal do Tocantins e apresentaram as seguintes características: $\mathrm{pH}-\mathrm{H}_{2} \mathrm{O}=5,4 ; \mathrm{Al}+\mathrm{H}=5,2$ cmol $_{\mathrm{c}}$ $\mathrm{dm}^{-3} ; \mathrm{Ca}^{2+}+\mathrm{Mg}^{2+}=2,5 \mathrm{cmol}_{\mathrm{c}} \mathrm{dm}^{-3} ; \mathrm{K}^{+}=18,6 \mathrm{ppm}$; $\mathrm{P}=10,2 \mathrm{ppm} ; \mathrm{SB}=2,5 \mathrm{cmol}_{\mathrm{c}} \mathrm{dm}^{-3} ; \mathrm{CTC}(\mathrm{T})=7,2$ $\mathrm{cmol}_{\mathrm{c}} \mathrm{dm}^{-3}$; matéria orgânica: $1,5 \%$; areia $=60,2$ $\%$; silte $=5,2 \%$; argila $=34,6 \%$.

O clima, segundo o método de Thornthwaite, é do tipo Aw, (clima úmido com moderada deficiência hídrica) (SEPLAN, 2003).

$\mathrm{O}$ experimento foi implantado sobre palhada de girassol. A calagem foi de $1.000 \mathrm{~kg} \mathrm{ha}^{-1}$ de calcário dolomítico com PRNT de 95\%, para a safra. A adubação de base aplicada no sulco de semeadura, para a safrinha, foi de $400 \mathrm{~kg} \mathrm{ha}^{-1} \mathrm{da}$ formulação 5-25-15 (NPK). Aos 30 dias após emergência (DAE), foi realizada a adubação de cobertura na dose de $60 \mathrm{~kg} \mathrm{ha}^{-1}$ de $\mathrm{N}$, o Boro foi aplicado via foliar aos 40 e 50 (DAE), na dosagem de $0,5 \mathrm{Kg}+0,5 \mathrm{~kg} \mathrm{ha}^{-1}$ (Castro e Oliveira, 2005). Antes da semeadura, procedeu-se o rebaixamento dos restos culturais do cultivo anterior (girassol) utilizando-se o implemento agrícola "Triton". 
Logo após procedeu-se a semeadura direta com subseqüiente dessecação de plantas invasoras, utilizando-se o herbicida Gliphosate na dosagem de $2 \mathrm{~L} \mathrm{ha}^{-1}$.

$\mathrm{O}$ delineamento experimental utilizado foi de blocos casualizados em esquema fatorial $4 \times 5$ (quatro épocas de semeadura $\mathrm{x}$ cinco cultivares de girassol), totalizando 20 tratamentos, com três repetições. Cada parcela foi constituída por 4 linhas de 5,0 m de comprimento, e espaçadas de $0,80 \mathrm{~m}$ entre linhas, total de $16 \mathrm{~m}^{2}$. Somente as duas linhas centrais foram consideradas como parcelas úteis para as avaliações.

As quatro épocas (EP) de semeadura foram: EP1 (15/03/2009), EP2 (28/03/2009), EP3 $(09 / 04 / 2009)$ e EP4 (01/05/2009) e cinco cultivares de girassol: Hélio 250 (H 250), Hélio 251(H 251), Hélio 358 (H 358), Hélio 360 (H 360) e Hélio 884 (H 884).

$\mathrm{O}$ desbaste foi realizado aos $15 \mathrm{DAE}$, deixando-se cinco plantas por metro. A área foi mantida livre de invasoras durante todo o desenvolvimento da cultura, por meio de capinas manuais. Para o controle da mancha de alternaria (Alternaria helianthi (Hansf.) Tubaki e Nishihara) foi utilizado o fungicida Difenoconazol na dose de $0,6 \mathrm{~L} \mathrm{ha}^{-1}$.

Os dados meteorológicos de temperatura, umidade relativa do ar e precipitação pluvial durante a execução do experimento encontram-se na Figura 1.

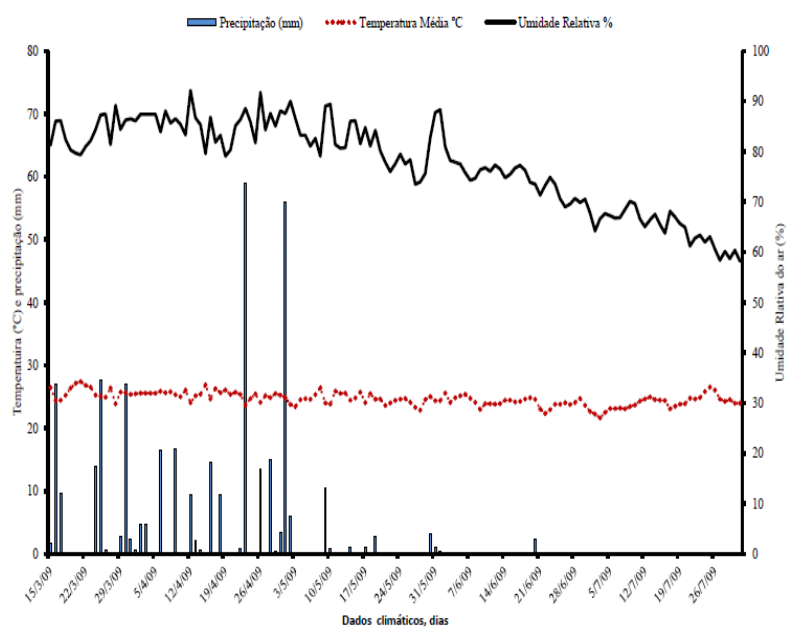

Figura 1 - Valores médios diários de temperaturas $\left({ }^{\circ} \mathrm{C}\right)$ e umidade relativa do ar (\%) e total diário de precipitação pluvial (mm) (Gurupi, TO, 2009).
As características avaliadas foram: florescimento (FLOR, em DAE): quando 50\% das plantas da parcela útil encontravam-se no estádio fenológico R4 (Connor e Hall, 1997); Altura da planta (AP, em $\mathrm{cm}$ ): medida da base até a inserção do capítulo, em cinco plantas da parcela útil; Diâmetro do capítulo (DC, em cm): média de cinco capítulos de cada parcela útil; Aquênios normais (AN, em \%): obtida a partir da contagem do número de Aquênios normais e chochos de cinco capítulos de cada parcela útil; Massa de mil Aquênios (P1000, em g): obtido pela contagem direta de 1000 Aquênios, pesado posteriormente em balança de precisão, Peso Hectolitro (Hect, em kg $100 \mathrm{~L}^{-1}$ ): quantificação da massa em volume conhecido com posterior extrapolação para 100 Litros, e Produtividade de Aquênios (PROD, em $\mathrm{kg} \mathrm{ha}^{-1}$ ): massa de Aquênios considerando-se todas as plantas da parcela útil (duas linha centrais), a 11\% de umidade.

Os dados experimentais foram submetidos à análise individual e conjunta de variância, com aplicação do teste $\mathrm{F}$ (Tabela 1). A análise conjunta foi realizada sob condições de homogeneidade das variâncias residuais. Para as comparações entre médias de tratamentos, foi utilizado o teste Tukey $(\mathrm{p} \leq 0,05)$, obtido a partir do aplicativo GENES (Cruz, 2006).

\section{RESULTADOS E DISCUSSÃO}

Verificou-se interação significativa a $1 \%$ e $5 \%$ pelo teste $\mathrm{F}$ para todas as características avaliadas (Tabela 1). Tal interação significativa indica que os ambientes influenciam de forma diferenciada o comportamento das cultivares, desta forma, realizou-se o desdobramento. 
Tabela 1. Análise de Variância conjunta das características FLOR - Número de dias para florescimento; AP - Altura de plantas; DC - Diâmetro de capítulos; AN - Porcentagem de aquênios normais; P1000 Massa de 1000 aquênios; Hect - Peso hectolitro e PROD - Produtividade de Aquênios, de cinco cultivares de girassol em quatro épocas de semeadura direta (safrinha), sobre palhada de girassol (Gurupi, Mar./ 2009).

\begin{tabular}{ccccccccc}
\hline \multicolumn{7}{l}{ Girassol cultivado sobre palhada de girassol } \\
\hline \multirow{2}{*}{ F.V. } & \multirow{2}{*}{ G.L.L } & \multicolumn{7}{c}{ Quadrado Médio } \\
\cline { 2 - 10 } & & FLOR & AP & DC & NA & P1000 & Hect & PROD \\
\hline Bloco/Ep. & 8 & 0,150 & 25,709 & 0,135 & 35,308 & 2,371 & 2,172 & 3421,9 \\
\hline Cultivar & 4 & $10,625^{\text {ns }}$ & $614,851^{* *}$ & $3,333^{\text {ns }}$ & $217,770^{\text {ns }}$ & $126,429^{*}$ & $39,503^{* *}$ & 1 \\
Época & 3 & $49,866^{* *}$ & $7454,907^{* *}$ & $91,110^{* *}$ & $3905,065^{* *}$ & $1409,198^{* *}$ & $609,499^{*}$ & 34259 \\
C x E & 12 & $3,325^{*}$ & $94,033^{* *}$ & $2,594^{* *}$ & $656,119^{* *}$ & $35,702^{* *}$ & $6,281^{*}$ & 62183, \\
\hline Resíduo & 32 & 1,525 & 22,667 & 0,530 & 8,52 & 2,990 & 2,451 & 2801,8 \\
\cline { 2 - 10 } Média & & 51,0 & 82,31 & 8,73 & 70,03 & 34,43 & 33,19 & 690,16 \\
\cline { 2 - 10 } C.V. & 2,42 & 5,78 & 8,34 & 4,16 & 5,02 & 4,71 & 7,66 \\
\hline
\end{tabular}

Para a característica número de dias para o florescimento (Tabela 2), obtiveram-se maiores médias na EP3, com 52,6 dias entre as cultivares. Backes et al. (2008), ao avaliar genótipos de girassol em diferentes épocas de semeadura obteve florescimento médio de 64,6 dias. De acordo com Castro e Farias, (2005) temperaturas baixas, baixa luminosidade e alta umidade prolongam o ciclo da cultura, atrasando a floração e a maturação fisiológica. Nas condições ambientais em que foram conduzidos os experimentos, temperatura, umidade relativa e luminosidade favoreceram a diminuição do ciclo da cultura, visto que houve redução média de aproximadamente 15 dias no florescimento, quando comparados com os resultados divulgados por Backes et al. (2008).

Comparando as cultivares dentro de cada época (Tabela 2), observou-se que a cultivar H884 esteve entre as mais tardias, nas épocas EP1, EP2 e EP4 a cultivar atingiu a maior média de 52,0 dias, enquanto a cultivar $\mathrm{H} 251$ esteve entre as mais precoces em todas as épocas, com médias de 49,0; 48,$3 ; 52,6$; e 49,0 dias. Valores semelhantes aos obtidos neste trabalho foram verificados por Silva et al. (2007) que obtiveram florescimento aos 52 DAE.

Tabela 2. Número de dias para o florescimento, Altura de plantas, Diâmetro de capítulos, Porcentagem de aquênios normais, Massa 1000 aquênios, Peso hectolitro e Produtividade de cinco cultivares de girassol em quatro épocas de semeadura direta (safrinha), sobre palhada de girassol (Gurupi, TO, mar./2009).

\begin{tabular}{|c|c|c|c|c|c|}
\hline \multirow{2}{*}{ Cultivares } & \multicolumn{4}{|c|}{ Épocas de semeadura } & \multirow{2}{*}{ Média } \\
\hline & EP1 & EP2 & EP3 & EP4 & \\
\hline & \multicolumn{4}{|c|}{ Florescimento } & \\
\hline H250 & $50,6 \mathrm{abAB}$ & $48,3 \mathrm{bB}$ & $53,0 \mathrm{bA}$ & $50,6 \mathrm{abAB}$ & 50,6 \\
\hline $\mathrm{H} 251$ & $49,0 \mathrm{bB}$ & $48,3 \mathrm{bB}$ & $52,6 \mathrm{bA}$ & $49,0 \mathrm{bB}$ & 49,7 \\
\hline H358 & $51,0 \mathrm{abB}$ & $48,6 \mathrm{bB}$ & $56,0 \mathrm{aA}$ & $51,0 \mathrm{abB}$ & 51,6 \\
\hline H360 & $50,0 \mathrm{abB}$ & $49,3 \mathrm{abB}$ & $53,6 \mathrm{abA}$ & $50,0 \mathrm{abB}$ & 50,7 \\
\hline H884 & $52,0 \mathrm{aA}$ & $52,0 \mathrm{aA}$ & $52,6 \mathrm{bA}$ & $52,0 \mathrm{aA}$ & 52,1 \\
\hline \multirow[t]{2}{*}{ Média } & 50,5 & 49,3 & 53,6 & 50,5 & \\
\hline & \multicolumn{4}{|c|}{ Altura de plantas } & \\
\hline $\mathrm{H} 250$ & $90,8 \mathrm{cA}$ & $88,4 \mathrm{aA}$ & $54,8 \mathrm{bcB}$ & $60,5 \mathrm{bB}$ & 73,63 \\
\hline H251 & $106,6 \mathrm{bA}$ & $98,5 \mathrm{aA}$ & $49,1 \mathrm{cC}$ & $71,0 \mathrm{abB}$ & 81,30 \\
\hline H358 & $103,2 \mathrm{bA}$ & $99,2 \mathrm{aA}$ & $47,3 \mathrm{cC}$ & $68,8 \mathrm{abB}$ & 79,63 \\
\hline
\end{tabular}




\begin{tabular}{|c|c|c|c|c|c|}
\hline $\begin{array}{l}\mathrm{H} 360 \\
\mathrm{H} 884\end{array}$ & $\begin{array}{l}105,2 \mathrm{bA} \\
121,1 \mathrm{aA}\end{array}$ & $\begin{array}{l}95,6 \mathrm{aA} \\
99,4 \mathrm{aB}\end{array}$ & $\begin{array}{l}63,4 \mathrm{abB} \\
73,2 \mathrm{aC}\end{array}$ & $\begin{array}{l}70,1 \mathrm{abB} \\
79,4 \mathrm{Ac}\end{array}$ & $\begin{array}{l}83,58 \\
93,28\end{array}$ \\
\hline Média & 105,38 & 96,23 & 57,56 & 69,96 & \\
\hline & \multicolumn{5}{|c|}{ Diâmetro do capitulo } \\
\hline $\mathrm{H} 250$ & $10,3 \mathrm{bA}$ & $10,40 \mathrm{aA}$ & $6,6 \mathrm{aB}$ & $6,8 \mathrm{bB}$ & 8,53 \\
\hline H251 & $10,4 \mathrm{bA}$ & $10,96 \mathrm{aA}$ & $5,3 \mathrm{bcC}$ & $7,0 \mathrm{bB}$ & 8,42 \\
\hline H358 & $10,5 \mathrm{bA}$ & $10,73 \mathrm{aA}$ & $4,6 \mathrm{cC}$ & $6,9 \mathrm{bB}$ & 8,18 \\
\hline H360 & $11,0 \mathrm{bA}$ & 9,93 aA & $7,2 \mathrm{aB}$ & $7,3 \mathrm{abB}$ & 8,86 \\
\hline $\mathrm{H} 884$ & $12,8 \mathrm{aA}$ & $10,86 \mathrm{aA}$ & $6,3 \mathrm{abD}$ & $8,3 \mathrm{aC}$ & 9,57 \\
\hline \multirow[t]{2}{*}{ Média } & 11,0 & 10,58 & 6,0 & 7,26 & \\
\hline & \multicolumn{5}{|c|}{ Aquênios normais } \\
\hline $\mathrm{H} 250$ & $50,8 \mathrm{cC}$ & $89,07 \mathrm{aB}$ & $92,0 \mathrm{aA}$ & $38,5 \mathrm{cD}$ & 67,59 \\
\hline $\mathrm{H} 251$ & $89,1 \mathrm{aA}$ & $71,75 \mathrm{bC}$ & $79,7 \mathrm{bB}$ & $56,7 \mathrm{aB}$ & 74,31 \\
\hline H358 & $60,5 \mathrm{bB}$ & $92,75 \mathrm{aA}$ & $54,6 \mathrm{cB}$ & $45,9 \mathrm{bC}$ & 63,44 \\
\hline H360 & 85,4 aA & $90,35 \mathrm{aA}$ & $61,2 \mathrm{cB}$ & $55,8 \mathrm{aD}$ & 73,19 \\
\hline $\mathrm{H} 884$ & $65,3 \mathrm{bC}$ & $88,94 \mathrm{aA}$ & $80,1 \mathrm{bB}$ & $43,5 \mathrm{bcD}$ & 69,46 \\
\hline \multirow[t]{3}{*}{ Média } & 70,22 & 86,57 & 73,52 & 48,08 & \\
\hline & \multicolumn{5}{|c|}{ Massa 1000 Aquênios } \\
\hline & $32,5 \mathrm{~dB}$ & $39,1 \mathrm{cA}$ & 23,1 bC & $22,3 \mathrm{cC}$ & 29,25 \\
\hline $\mathrm{H} 251$ & $35,5 \mathrm{cdB}$ & 48,2 abA & $25,5 \mathrm{bC}$ & $23,9 \mathrm{bcC}$ & 33,28 \\
\hline H358 & $41,1 \mathrm{bB}$ & 49,9 aA & $24,6 \mathrm{bC}$ & $27,4 \mathrm{abC}$ & 35,75 \\
\hline $\mathrm{H} 360$ & $37,1 \mathrm{bcB}$ & $48,0 \mathrm{abA}$ & $33,1 \mathrm{aC}$ & $27,2 \mathrm{bD}$ & 36,35 \\
\hline H884 & $47,2 \mathrm{aA}$ & $45,1 \mathrm{bA}$ & $25,8 \mathrm{bC}$ & $31,4 \mathrm{aB}$ & 37,38 \\
\hline \multirow[t]{3}{*}{ Média } & 38,68 & 46,06 & 26,42 & 26,44 & \\
\hline & \multicolumn{5}{|c|}{ Peso hectolitro } \\
\hline & & & -gramas--- & & - \\
\hline $\mathrm{H} 250$ & $31,9 \mathrm{bA}$ & $34,9 \mathrm{bA}$ & $32,0 \mathrm{aA}$ & $21,2 \mathrm{bB}$ & 30,0 \\
\hline $\mathrm{H} 251$ & 36,8 baA & $39,6 \mathrm{aA}$ & $34,9 \mathrm{aB}$ & $24,5 \mathrm{abC}$ & 33,9 \\
\hline $\mathrm{H} 358$ & $37,0 \mathrm{baA}$ & $38,4 \mathrm{abA}$ & $34,8 \mathrm{aB}$ & $24,6 \mathrm{abC}$ & 33,7 \\
\hline $\mathrm{H} 360$ & $39,1 \mathrm{aA}$ & $41,4 \mathrm{aA}$ & $32,1 \mathrm{aB}$ & $26,0 \mathrm{aC}$ & 34,6 \\
\hline H884 & $37,6 \mathrm{aA}$ & $40,0 \mathrm{aA}$ & $31,5 \mathrm{aB}$ & $25,1 \mathrm{aC}$ & 33,5 \\
\hline \multirow[t]{3}{*}{ Média } & 36,4 & 38,89 & 33,0 & 24,3 & \\
\hline & \multirow{2}{*}{\multicolumn{5}{|c|}{ Produtividade }} \\
\hline & & & & & \\
\hline $\mathrm{H} 250$ & $444,8 \mathrm{cB}$ & $1305,0 \mathrm{cA}$ & $321,9 \mathrm{bC}$ & $316,7 \mathrm{cC}$ & 597,1 \\
\hline $\mathrm{H} 251$ & $465,6 \mathrm{cB}$ & $1470,2 \mathrm{abA}$ & $165,0 \mathrm{cD}$ & $302,6 \mathrm{cC}$ & 600,8 \\
\hline H358 & $529,6 \mathrm{cB}$ & $1384,9 \mathrm{bcA}$ & $255,1 \mathrm{bcD}$ & $381,7 \mathrm{bcC}$ & 637,8 \\
\hline $\mathrm{H} 360$ & $721,3 \mathrm{bB}$ & $1192,4 \mathrm{dA}$ & $591,7 \mathrm{aC}$ & $482,2 \mathrm{bD}$ & 746,9 \\
\hline H884 & $931,1 \mathrm{aB}$ & $1571,8 \mathrm{aA}$ & $356,2 \mathrm{bD}$ & $613,0 \mathrm{aC}$ & 868,0 \\
\hline Média & 618,5 & 1384,8 & 337,9 & 419,2 & \\
\hline
\end{tabular}

Médias seguidas por uma mesma letra maiúscula na linha e minúscula na coluna, não diferem significativamente pelo teste Tukey, a $5 \%$.

Para a característica altura de plantas (Tabela 2), obteve-se nas EP1 e EP2 superioridade significativa para todos as cultivares, exceto para a cultivar H884 na EP2. Comparando as cultivares dentro de cada época, observou-se maior altura para a cultivar $\mathrm{H} 884$ em todas as épocas, entretanto, na EP2 não houve diferenças entre as cultivares, na EP3 não diferiu do H360 e na EP4 não diferiu das cultivares H251, H358 e H360. 
Silva et al. (2009), estudando redução de espaçamento na entre linha em híbridos de girassol em Rio Verde (GO) obteve altura média de 92,6 $\mathrm{cm}$, comparado com os valores obtidos neste trabalho (Tabela 2), verifica-se que nas épocas EP1 e EP2 apenas o H250 está abaixo da média obtida pelo autor citado acima, nas épocas EP3 e EP4 todos os resultados obtidos estão abaixo, estes menores valores podem ser explicados pelo maior número de verânicos e intensidade da estiagem ocorrida.

Para a característica diâmetro de capítulos (Tabela 2 ), observa-se entre as épocas de semeadura, que as épocas EP1 e EP2 obtiveram as maiores médias. Comparando-se as cultivares dentro de cada época (Tabela 2), observou-se que a cultivar H884 obteve diâmetro de capítulo significativamente superior às demais cultivares na época EP1, EP3 e EP4, sendo que nas duas ultimas épocas não se verificou diferença entre as cultivares $\mathrm{H} 360$ e H884. Tomich et al., (2003) obteve em condições de safrinha, capítulos com $17,3 \mathrm{~cm}$ de diâmetro, superiores aos valores obtidos neste trabalho. Tal fato pode ter ocorrido em função da ocorrência de Alternaria helianthi durante a fase de desenvolvimento do capítulo e posteriormente por déficit hídrico durante enchimento dos aquênios (Figura 1).

Para a característica porcentagem de aquênios normais (Tabela 2), quando comparando as épocas de semeadura dentro de cada cultivar, observou-se menores porcentagens de aquênios normais quando os genótipos foram cultivados na época EP4 para as cultivares H250, H358, H360 e H884. Segundo Amorim et al., (2008) para condições de safrinha a porcentagem de aquênios normais é próxima de $75 \%$. Neste trabalho, como pode ser observado na Tabela 1, a porcentagem de aquênios normais oscilou em torno deste valor.

Quanto às médias das cultivares (Tabela 2), observou-se que a cultivar $\mathrm{H} 251$ obteve os maiores resultados nas EP1 e EP4, não diferindo significativamente nas duas ocasiões da cultivar H360. As cultivares H358, H360 e H884 obtiveram os maiores resultados na EP2, acima de $85 \%$ de aquênios normais, já o H250 diferiu significativamente de todos os outros com $92 \%$ de aquênios normais na EP4. Verificou-se variabilidade entre as cultivares, em todas as épocas, evidenciando que as cultivares testados apresentam elevada variabilidade genética para esta característica, constatada pelo elevado efeito ambiental na manifestação da característica.

Para a variável massa de mil aquênios (Tabela 2), obtiveram-se os maiores resultados na EP2, seguido da EP1, diferenciando significativamente das EP3 e EP4. Silva et al., (2009) obteve média $59,7 \mathrm{~g}$ para massa de mil aquênios, a qual foi $22,85 \%$ maior comparado com a melhor média obtida pela EP2, tal fato pode ter ocorrido em decorrência da pouca disponibilidade hídrica ocorrida no período de enchimento dos aquênios.

Quanto às cultivares dentro de cada época, observou-se os maiores resultados com cultivar H884 nas épocas EP1 e EP4, o H358 na EP2 e o H360 na EP3. Amorim et al., (2008) ao estudar correlações e análise de trilha em girassol em condições de safra, obteve média para massa de mil aquênios de 34,41 g, comparado com as maiores médias obtidas pelas cultivares acima, verifica-se que o $\mathrm{H} 884$ e $\mathrm{H} 358$ tem médias maiores nas EP1 e EP2, evidenciando possuir potencial para produzir aquênios mais densos, quando as condições ambientais forem favoráveis. Para a característica peso hectolitro quando se comparam as épocas de semeadura em cada cultivar (Tabela 2), aquênios mais pesados foram obtidos nas épocas EP1 e EP2, sendo, portanto significativamente melhores as demais épocas. Valores semelhantes de peso hectolitro foram obtidos por Amorim et al., (2008).

Com relação às cultivares dentro de cada época (Tabela 2), observou-se que a cultivar H250 destacou-se negativamente, ou seja, desenvolveu aquênios significativamente inferiores em densidade comparado às demais cultivares, em todas as épocas, exceto na EP2, em que não houve diferenças significativas entre as cultivares (Tabela 2).

Para a produtividade de aquênios (Tabela 2), obteve-se maiores produtividades na época EP2, seguido da EP1, as duas diferiram significativamente das demais épocas de semeadura. Ressalta-se que à medida que a semeadura da cultura principal foi atrasada, houve tendência a redução na produtividade da cultura produzida como safrinha. Esta tendência pode ser explicada, possivelmente, pela redução gradativa da disponibilidade hídrica, o que possivelmente desfavoreceu as cultivares nas duas últimas épocas de semeadura (Figura 1). Produtividade de 1.861 
$\mathrm{kg} \mathrm{ha}^{-1}$ foi obtida por Backes et al., (2008) também em condições de safrinha.

Quanto às cultivares dentro de cada época de semeadura (Tabela 2), verificou-se que a cultivar H884 obteve as maiores produtividades nas EP1, EP2, e EP4, e a cultivar H360 na EP3.

\section{CONCLUSÕES}

Houve redução em todas as variáveis avaliadas com o retardamento da semeadura;

Maiores produtividades de aquênios foram obtidas quando o girassol foi implantado em 28 de março; A cultivar H884 teve o melhor desempenho para a maioria das variáveis analisadas e épocas de semeadura.

\section{AGRADECIMENTOS}

A Secretaria de Ciência e Tecnologia do Estado do Tocantins, pela concessão de bolsa auxílio mestrado do Programa de Ajuda a Pós-Graduação (PAPG).

\section{RESUMO}

O girassol (Helianthus annuus L.) é considerado uma cultura de grande plasticidade, apresenta características importantes como tolerância a diversos fatores abióticos, à seca e a temperaturas extremas. Nesse contexto a cultura pode ser mais uma opção as safrinhas, que com semeadura direta otimiza o uso da terra, máquinas, mão-de-obra, e criação de empregos na região produtora. $\mathrm{O}$ objetivo deste trabalho foi avaliar cultivares de girassol (Hélio 250 - H250, Hélio 251 H251, Hélio 358 - H358, Hélio 360 - H360 e Hélio 884 - H884) em quatro épocas de semeadura (EP1 15/03/2009; EP2 - 28/03/2009; EP3 - 09/04/2009 e EP4 - 01/05/2009) direta sobre palhada de girassol, safrinha 2009, em Gurupi, Sul do Estado do Tocantins. O delineamento experimental utilizado foi de blocos casualizados, em esquema fatorial $4 \times 5$ (época de semeadura $\mathrm{x}$ cultivares), com três repetições. Verificouse interação significativa entre épocas de semeadura e cultivares para todas as características avaliadas. Houve redução em todas as variáveis avaliadas com retardamento da semeadura. Maiores produtividades de aquênios foram obtidas quando o girassol foi cultivado na segunda época de semeadura. A cultivar H884 teve o melhor desempenho para a maioria das variáveis analisadas nas diferentes épocas de semeadura.

Palavras-chave: Helianthus annuus L., cultivares, palhada

\section{REFERÊNCIAS}

Abreu, J. B. R.; Menezes, J. B. O. X.; Scofield, H. L.; Scolforo, L,; Araújo, L. A.; Souza, M. M, Junior, E. P. N.; Santos, A. P. (2001), Avaliação da produção de capítulos e de matéria seca total de quatro cultivares de girassol (Helianthus annuus). In: $14^{a}$ Reunião Nacional de Pesquisa de Girassol. Simpósio Nacional Sobre a Cultura do Girassol, Rio Verde. Resumos, Rio Verde: FESURV/IAM. 1, 48- 49.

Amorim, E. P.; Ramos, N. R.; Ungaro, M. R. G.; Kiihl, T. A. M. (2008), Correlações e análises de trilha em girassol. Bragantia, 67, 307-316.

Backes, L. R.; Souza, A. M.; Balbinot Junior, A. A.; Gallotti, G. J. M.; Bavaresco, A. (2008), Desempenho de cultivares de girassol em duas épocas de plantio de safrinha no planalto norte catarinense. Scientia Agraria, 9, 41-48.

Castiglioni, V. B. R. e Oliveira, M. F. (2005), Melhoramento do girassol. In: Melhoramento de espécies cultivadas. Viçosa, 2, 393-427.

Castro, C. e Farias, J. R. B. (2005), Ecofisiologia do girassol. In: Girassol no Brasil. Londrina: Embrapa Soja, 1, 501-546.

Castro, C. e Oliveira, F. A. (2005), Nutrição e adubação do girassol. In: Girassol no Brasil. Londrina: EMBRAPA SOJA, 1, 317-374.

CONAB. (2010), Companhia Nacional de Abastecimento. Acompanhamento da safra brasileira de grãos 2009/2010: oitavo levantamento, maio/2010. 2010. Disponível em: $<\mathrm{http} / / / \mathrm{www}$. conab.gov.br>. Acesso em: 06 maio 2010 .

Connor, J. D. e Hall, A. J. (1997), Sunflower physiology. In: Sunflower technology and production. Madison: ASA-CSSA-SSSA, 1, 113181. (Series of monographs, 35).

Costa, V. C. A.; Silva, F. N.; Ribeiro, M. C. C. (2000), Efeito de épocas de semeadura na germinação e desenvolvimento em girassol (Helinathus annuus L.). Revista Científica Rural, 5, 154-158. 
Cruz, C. D. (2006), Programa Genes - Aplicativo computacional em genética e estatística. Viçosa: UFV, Imprensa Universitária. 285p.

EMBRAPA. (1999), Empresa Brasileira de Pesquisa Agropecuária. Centro Nacional de Pesquisa de Solos. Sistema brasileiro de classificação de solos. Brasília, DF: Embrapa, 412p.

Gomes, E. M.; Ungaro, M. R. G.; Vieira, D. B. (2004), Demanda hídrica do girassol (Helianthus annuus L.) obtida em diferentes fases da cultura. In: CONGRESSO LATINOAMERICANO DE HIDRÁUlICA, 21., 2004, São Pedro. Anais... São Pedro: IAHR, 2004. 1-11.

Lazzarotto, J. J.; Roessing, A. C.; Mello, H. C. (2005), O agronegócio do girassol no mundo e no Brasil. In: Girassol no Brasil. Londrina: Embrapa Soja, 1, 15-42.

Leite, R. M. V. B. de C.; Brighenti, A. M.; Castro, C. (2005), Girassol no Brasil. Londrina: Embrapa Soja, 1, 641p.

Porto, W. S.; Carvalho, C. G. P.; Pinto, R. J. B. (2007), Adaptabilidade e estabilidade como critérios para seleção de genótipos de girassol. Pesquisa Agropecuária Brasileira, 42, 491-499.

Silva, A. G.; Pires, P.; Morães, E. B.; Oliveira, A. C. B.; Carvalho, C. G. P. (2009), Desempenho de híbridos de girassol em espaçamentos reduzidos. Semina: Ciências Agrárias, 30, 31-38.
Silva, M. L. O.; Faria, M. A.; Morais, A. R.; Andrade, G. P.; Lima. E. M. C. (2007), Crescimento e produtividade do girassol cultivado na entressafra com diferentes lâminas de água. Revista Brasileira de Engenharia Agrícola Ambiental, 11, 482-488.

Smiderle, O. J.; Mourão Junior, M.; Gianluppi, D. (2005), Avaliação de cultivares de girassol em savana de Roraima. Acta Amazonica, 35, 331-336.

SEPLAN. (2003), Secretaria do Planejamento e Meio Ambiente do Tocantins. Atlas do Tocantins: Subsídios ao planejamento da gestão territorial. 3 . Ed. Palmas-TO: SEPLAN, 49p.

Tomich, T. R.; Rodrigues, J. A. S.; Gonçalves, L. C.; Tomich, R. G. P.; Carvalho, A. U. (2003), Potencial forrageiro de cultivares de girassol produzidos na safrinha para ensilagem. Arquivo Brasileiro de Medicina Veterinária e Zootecnia, 55, 756-762.

Ungaro, M. R. G. (2006), Potencial da cultura do girassol como fonte de matéria-prima para $\mathrm{o}$ programa nacional de produção e uso de biodiesel. In: Agronegócio de plantas oleaginosas: matériasprimas para o biodiesel. Piracicaba: ESALQ, 1, 57-80p.

Villalba, E. O. H. Recomendação de nitrogênio, fósforo e potássio para girassol sob sistema plantio direto no Paraguai. Dissertação (Mestrado em Ciências do solo) - Universidade Federal de Santa Maria, Santa Maria, 2008. 